\section{Urologia \\ Internationalis}

Imran Ahmad ${ }^{\text {a }}$

Robert J. Barnetson ${ }^{b}$ Nalagatla Sarath Krishnac

${ }^{a}$ Beatson Institute for Cancer Research and Departments of ${ }^{b}$ Pathology and

'Urology, Southern General Hospital, Glasgow, UK
Urol Int 2008;81:247-251

DOI: $10.1159 / 000151398$

\title{
Keratinizing Squamous Metaplasia of the Bladder: A Review
}

\section{Key Words}

Keratinizing squamous metaplasia • Squamous cell carcinoma

\section{Abstract}

Aims: Keratinizing squamous metaplasia is infrequently found in bladder biopsies and its clinical significance remains unclear, with studies linking it to the development of invasive squamous cell carcinoma. Once diagnosed, there is a dilemma how to treat and follow-up this group. Methods: We reviewed the literature on the topic with particular emphasis on natural history, management and subsequent follow-up. Results: Keratinizing squamous metaplasia of the bladder is rare. Pathognomonic findings on biopsy are required to confirm the diagnosis. Both synchronous diagnosis of urothelial tumour and subsequent tumour development on follow-up has been identified. Risk of malignant transformation increases in the presence of dysplasia as well as with extensive keratinization. Lesions should be treated with local transurethral resection. Considering the lack of evidence cystectomy cannot be justified for those with extensive lesions. Conclusion: Currently there is not enough data to identify keratinizing squamous metaplasia of the bladder as a pre-malignant condition; this term being reserved for those with obvious histological dysplasia. However at present all patients should undergo regular followup.

Copyright $\odot 2008$ S. Karger AG, Basel
(C) 2008 S. Karger AG, Basel $0042-1138 / 08 / 0813-0247 \$ 24.50 / 0$

Fax +41613061234 E-Mail karger@karger.ch www.karger.com

\section{Introduction}

Keratinizing squamous metaplasia is infrequently found in bladder biopsies and its clinical significance remains unclear, with some studies linking it to the development of invasive squamous cell carcinoma (SCC).

In this review we analyzed all the literature on this topic to investigate the link between keratinizing squamous metaplasia and the risk of subsequent development of invasive cancer. In particular we tried to find whether there was any consensus over the management and follow-up of these patients.

\section{Materials and Methods}

We reviewed the literature on keratinizing squamous metaplasia, searching using the keywords 'keratinizing (keratinising) squamous metaplasia', 'leukoplakia' and 'squamous cell cancer'. A Medline search of the English literature from January 1960 to December 2006 inclusive was done on OVID. All relevant articles were studied in full.

\section{Results}

\section{Incidence and Aetiology}

Keratinizing squamous metaplasia of the bladder is rare. The incidence has been reported as 1:10,000 of hospital admissions [1]. However analysis of the literature 
suggests it may be commoner than this figure [2]. There are numerous presumed aetiological factors, all of which result in chronic irritation of the bladder mucosa.

Urinary Tract Infections. Worldwide, schistosomiasis is the commonest cause of squamous metaplasia. Before anti-tuberculous therapy, urinary tract tuberculosis was commonly associated with squamous metaplasia of the urinary tract. This was also seen with syphilis before the widespread use of penicillin. Currently Escherichia coli, Proteus and Streptococcus faecalis are the 3 most identified organisms in patients with squamous metaplasia. Traditionally the literature cites a rate of between 49 and $100 \%$ of proven infection in these patients [1-4]. It is postulated that urinary infections cause keratinizing squamous metaplasia in response to the inflammatory trauma. Furthermore Ozbey et al. [5] suggested that the defects on the glycosaminoglycan layer of the bladder surface, which is created by non-keratinizing trigonal squamous metaplasia, may lead to the development of infection.

Urinary Tract Irritants. Chronic irritants associated with squamous metaplasia include: indwelling catheters, urinary calculi, urinary outflow obstruction, fistula, tumours, bladder extrophy, neurogenic bladder, previous bladder surgery and vitamin A deficiency [3]. Akdas et al. [6] observed squamous cell metaplasia progressing to SCC in a patient receiving radiation therapy for transitional cell carcinoma.

Genetic Factors. The only case in the literature refers to Mueller et al.'s [4] description of 3 women in a family who presented with urothelial leukoplakia with no underlying aetiological factor.

\section{Clinical Features}

Patients usually present with non-specific irritative urinary symptoms including haematuria, dysuria, urgency and frequency $[2,7,8]$. There is a slight male-tofemale predominance [9]. In their study, Khan et al. [2] identified 1 patient who actually passed white flakes in the urine.

Keratinizing squamous metaplasia most often occurs in the bladder. Benson [7] in his study identified 108 patients with leukoplakia lesions: 24 had upper urinary tract lesions, 78 had bladder lesions and 10 had urethral metaplasia lesions ( 1 with renal and bladder involvement, 3 with bladder and urethral involvement, and 1 with urethral and renal involvement). Reece et al. [10] identified it twice as commonly in the bladder compared with the renal pelvis and ureter.

\section{Pathology}

The pathological features of keratinizing squamous metaplasia were first described by Rokitansky in 1862 . He described an excessive formation of squamous epithelium with desquamation and piling of the epithelium, identifying this lesion as a 'cholesteatoma'. The definitive description came later from McDonald [11], who put it simply as cornification of a non-cornifying membrane.

At cystoscopy keratinizing squamous metaplasia appears as an area of hyperaemia with pearl-like plaques, which appear to float over the surrounding inflamed urothelium. These plaques can either be discrete or diffuse, blending imperceptibly into the surrounding epithelium. When these pearly plaques are disturbed, the underlying surface appears papillary and bleeds easily. Keratinization can affect any part of the bladder, including the prostatic urethra, but usually spares the ureteric orifices $[2,12]$.

Microscopically, the urothelium is replaced by stratified squamous epithelium which can be classified into keratinizing and non-keratinizing subtypes (fig. 1, 2). In the keratinizing type, there is an overlying layer of keratin. The non-keratinizing type includes the so-called vaginal type seen in females at the trigone and bladder neck. This is considered a normal anatomical variant under hormonal influence $[5,13]$. Other non-invasive squamous lesions of the bladder include verrucous squamous hyperplasia, squamous papilloma, condyloma accuminatum and SCC in situ [9]. As well as confirming the diagnosis, biopsy is required to exclude macroscopic mimics, which include fungal cystitis, alkaline encrustation, malakoplakia and amyloid [2].

Keratinizing squamous metaplasia appears to be a significant risk factor for the development of vesical carcinoma $[2,5,7,9,14,15]$. In fact, concomitant invasive squamous carcinoma is found in a significant proportion of cases at the time of diagnosis $[2,9]$. Whilst there is usually no nuclear atypia, a spectrum of dysplastic changes may be seen ranging from low- to high-grade dysplasia and squamous carcinoma in-situ. Therefore, whilst not a premalignant lesion per se, keratinizing squamous metaplasia is presumably a pre-neoplastic condition [16]. However, its rarity in the bladder makes the stepwise development from metaplasia through dysplasia and carcinoma in situ to invasive carcinoma more difficult to identify than in the uterine cervix, where it is a well-known phenomenon [2].

\section{Natural History}

Various theories have been postulated as to why squamous metaplasia may progress to invasive bladder cancer. 


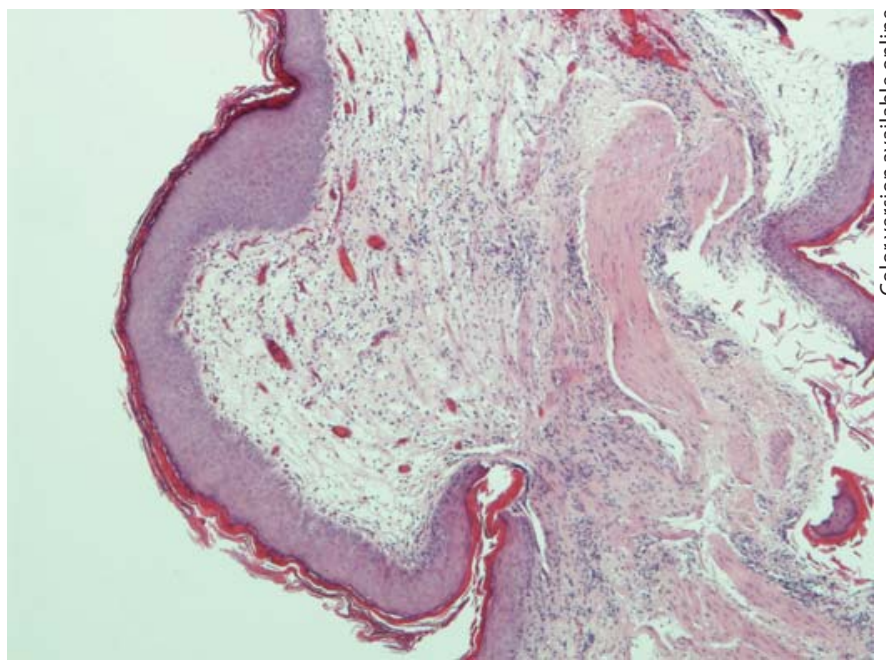

Fig. 1. Bladder biopsy surfaced by keratinized squamous epithelium with oedematous and mildly inflamed submucosa. HE. $\times 4$.

Mueller et al. [4] reported inflammatory changes in the bladder wall underlying areas of keratinizing squamous metaplasia. Electron microscopic studies reveal that squamous epithelium lacks tight inter-cellular junctions in contrast to the transitional epithelium. Thus one may presume that urine penetrates into the submucosal layer of the bladder causing inflammatory changes, with extensive bladder involvement causing contraction and non-compliance.

Roehrborn et al. [17] reported keratinizing squamous metaplasia progressing to SCC in a defunctionalized bladder 19 years after urinary diversion. The conclusion they reached was that once the initial metaplasia of the transitional epithelium of the urinary tract has occurred, chronic irritation (urine) is not required to cause further progression to SCC.

It is well recognized that squamous metaplasia and the SCC of the bladder frequently co-exist. The incidence of squamous metaplasia associated with tumour at the time of diagnosis is between 9 and $22 \%[2,7,18]$. The commonest malignancy associated with squamous metaplasia is SCC. Other associated types include transitional cell carcinoma and undifferentiated carcinoma as well as reports of glandular and even sarcomatous malignancies $[2,7]$.

Holley and Mellinger [19] described the first case of SCC developing in a patient undergoing follow-up. Ozbey et al. [5] performed follow-up studies in non-keratinizing $(\mathrm{n}=2)$ and keratinizing squamous metaplasia $(\mathrm{n}=2)$.

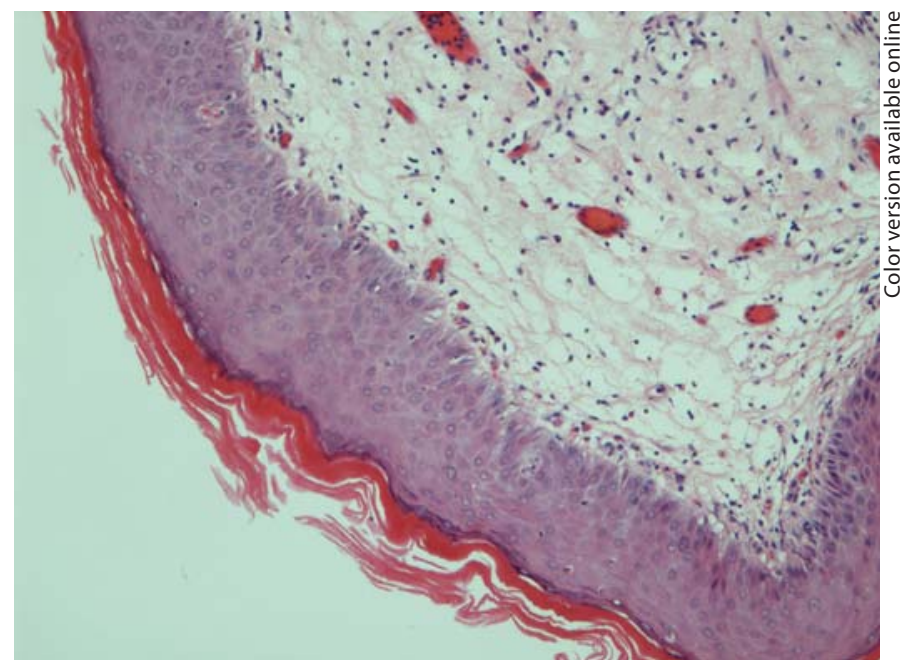

Fig. 2. Higher power view of the same biopsy showing metaplastic squamous epithelium. Note the lack of cytological atypia. HE. $\times 10$.

Neither of the non-keratinizing patients had any subsequent neoplastic changes, but 1 patient with keratinizing squamous metaplasia developed urothelial carcinoma with squamous differentiation.

Khan et al. [2] described in their cohort 6 of 11 patients with extensive and 2 of 16 with limited squamous keratinizing metaplasia developing subsequent bladder cancer. Six of these 8 patients had advanced cancer leading to an early death.

Guo et al. [9] followed up 4 patients with squamous metaplasia, 2 of whom developed urothelial carcinoma with squamous features.

Khan et al.'s [2] retrospective review over 54 years suggests the latent period for development for carcinoma is variable (4-28 years). They found that patients with synchronous squamous metaplasia and carcinoma presented at ages equivalent to normal bladder cancer incidence age curves (mean 62.5 years). In their study, those who developed metachronous carcinoma had been diagnosed with squamous metaplasia at a younger age but developed carcinoma after a long latent period. Their mean age at diagnosis of carcinoma was 64.5 years, similar to the age at which squamous metaplasia and carcinoma were diagnosed simultaneously.

There is still a paucity of data regarding whether keratinizing squamous metaplasia should be considered as a pre-malignant condition (table 1). However the recent International Consultation on the diagnosis of Non-Invasive Urothelial Neoplasms in 2002 considered keratiniz- 
Table 1. Incidence of synchronous cancer and progression to cancer of those with keratinizing squamous metaplasia

\begin{tabular}{|c|c|c|c|c|}
\hline Author & Patients & $\begin{array}{l}\text { Synchronous } \\
\text { cancer }\end{array}$ & Progression & Follow-up \\
\hline O’Flynn et al., 1967 [18] & 20 & & $2(10)$ & \\
\hline Reece et al., 1975 [10] & 44 & $10-20 \%$ & & \\
\hline Walts et al., 1977 [20] & 1 & & 1 & 6 years \\
\hline Morgan et al., 1980 [3] & 32 & & $9(28)$ & 20 years \\
\hline DeKock et al., 1981 [21] & 17 & & $3 / 17(17)$ & \\
\hline Zachwiej et al., 1981 [22] & 1 & & 1 & 15 years \\
\hline Benson et al., 1984 [7] & 108 & $23 / 108(21)$ & $18 / 85(21)$ & 35 years \\
\hline Roehrborn et al., 1988 [17] & 1 & & 1 & 19 years \\
\hline Kvist et al., 1992 [15] & 36 & $38 \%$ & & \\
\hline Ozbey et al., 1999 [5] & 2 & & $1(50)$ & \\
\hline Khan et al., 2002 [2] & 34 & 4 & $8(24)$ & $4-28$ years \\
\hline Guo et al., 2006 [9] & 4 & & $2(50)$ & 3 and 14 months \\
\hline
\end{tabular}

Unless otherwise stated, figures are numbers with percentages in parentheses.

ing squamous metaplasia as a presumed pre-neoplastic condition [16].

\section{Management}

There are reports of resolution of squamous metaplasia of the bladder, whether spontaneously or after some form of treatment. O'Flynn et al. [18] treated 10 cases with complete transurethral resection and fulguration and observed no recurrence during 3-5 year follow-up. These findings have been replicated in further studies $[2,3]$.

Reece et al. [10] reported spontaneous resolution of squamous metaplasia in 5 of 44 patients. Mueller et al. [4] noticed resolution of clinical symptoms as well as improvement of macroscopic and microscopic appearances after 6 months of therapy with sodium pentosanpolysulphate.

\section{Follow-Up}

Keratinizing squamous metaplasia may be limited or extensive. The natural history of the limited lesion is favourable, and potentially curable. In contrast, those with extensive keratinization may have a higher risk of cancer development, bladder contraction and upper urinary tract obstruction.

To ensure early detection of tumour one should carry out annual cystoscopy and multiple biopsies even if initial examination does not reveal dysplasia [2]. Treatment of choice is transurethral resection [2]. Given the lack of evidence at present it is not justified to advise cystectomy for patients with extensive squamous metaplasia alone.

\section{Conclusion}

Keratinizing squamous metaplasia appears to be a response to chronic irritation of the bladder. At present this process should not be considered a pre-malignant condition; this term being reserved for intra-epithelial neoplasia. There is however an increased risk of neoplasia in these patients, especially those with extensive lesions. Regular follow-up with cystoscopy and biopsy is indicated. Lesions should be treated with transurethral resection. Cystectomy is currently not considered standard treatment.

References

1 Connery DB: Leukoplakia of the urinary bladder and its association with carcinoma. J Urol 1953;69:121-127.

-2 Khan MS, Thornhill JA, Gaffney E, Loftus B, Butler MB: Keratinizing squamous metaplasia of the bladder: natural history and rationalization of management based on review of 54 years experience. Eur Urol 2002;42: $469-474$

-3 Morgan RJ, Cameron KM: Vesical leukoplakia. Br J Urol 1980;52:96-100.

4 Mueller SC, Thueroff JW, Rumpelt HJ: Urothelial leukoplakia: new aspects of aetiology and therapy. J Urol 1987;137:979-983.

5 Ozbey I, Aksoy Y, Polat O, Bicgi O, Demirel A: Squamous metaplasia of the bladder: findings in 18 patients and review of the literature. Int Urol Nephrol 1999;31:457-461. 
6 Akdas A, Turkeri L: The impact of squamous metaplasia in transitional cell carcinoma of the bladder. Int Urol Nephrol 1991;23:333336.

7 Benson Jr RC, Swanson SK, Farrow GM: Relationship of leukoplakia to urothelial malignancy. J Urol 1984;131:507-511.

$\checkmark 8$ Højgaard AD, Jessen AL: A case of vesical leukoplakia. Acta Obstet Gynecol Scand 1991;70:623-624.

9 Guo CC, Fine SW, Epstein JI: Noninvasive squamous lesions in the urinary bladder. Am J Surg Pathol 2006;30:883-891.

10 Reece RW, Koontz WW Jr: Leukoplakia of the urinary tract: a review. J Urol 1975;114: 165-171.

11 Marion G: Leukoplakia of the bladder. J Urol 1920;9:257-261.

12 Abeshouse BS, Tankin LH: Leukoplakia of the renal pelvis and bladder. J Urol 1953;76: 330-337.

13 Wiener DP, Koss LG, Sablay B, Freed SZ: The prevalence and significance of Brunn's nests, cystitis cystica and squamous metaplasia in normal bladders. J Urol 1979;122:317-321.
14 Delnay KM, Stonehill WH, Goldman H, Jukkola AF, Dmochowski RR: Bladder histological changes associated with chronic indwelling urinary catheter. J Urol 1999;161: 1106-1108; discussion 1108-1109.

15 Kvist E, Sjolin KE, Laursen H, Orntoft TF, Sanchez Sturmer MA: Squamous metaplasia of the bladder urothelium. A retrospective study of 36 patients. AMPIS 1992;100:650654.

16 Lopez-Beltran A, Cheng L, Andersson LC, Brausi M, De Matteis A, Montironi R, Sesterhenn I, van det Kwast T, Mazerolles C: Preneoplastic non-papillary lesions and conditions of the urinary bladder. An update based on the Ancona International Consultation. Virchows Arch 2002;440:3-11.

-17 Roehrborn CG, Teigland CM, Spence HM: Progression of leukoplakia of the bladder to squamous cell carcinoma 19 years after complete urinary diversion. J Urol 1988;140: 603-604.
8 O'Flynn JD, Mullaney J: Leukoplakia of the bladder. A report on 20 cases, including 2 cases progressing to squamous cell carcinoma. Br J Urol 1967;39:461-471.

19 Holley PS, Mellinger GT: Leukoplakia of the bladder and carcinoma. J Urol 1961;86:235241.

20 DeKock MLS, Anderson CK, Clark PB: Vesical leukoplakia progressing to squamous cell carcinoma in women. Br J Urol 1981;53:315317.

21 Walts AE, Sacks SA: Squamous metaplasia and invasive epidermoid carcinoma of bladder. Urology 1977;9:317-320.

22 Zachwiej J, Witeska A, Plaszczynski J: Tumor of the urinary bladder preceded by vesical leukoplakia. Int Urol Nephrol 1981;13: 147-152.

23 Hodder SL, Mahmoud AA, Sorenson K, Weinert DM, Stein RL, Ouma JH, Koech D, King CH: Predisposition to urinary tract epithelial metaplasia in Schistosoma haematobium infection. Am J Trop Med Hyg 2000; 63:133-138. 